\title{
Functional Nicotinic Acetylcholine Receptors That Mediate Ganglionic Transmission in Cardiac Parasympathetic Neurons
}

\author{
Steve Bibevski, ${ }^{1}$ Yuefang Zhou, ${ }^{2}$ J. Michael McIntosh, ${ }^{3}$ Richard E. Zigmond, ${ }^{2}$ and Mark E. Dunlap ${ }^{1,4}$ \\ Departments of ${ }^{1}$ Physiology and Biophysics and ${ }^{2}$ Neurosciences, Case Western Reserve University, Cleveland, Ohio \\ 44106, '3epartments of Biology and Psychiatry, University of Utah, Salt Lake City, Utah 84112, and 4Department of \\ Medicine-Cardiology, Veterans Affairs Medical Center, Cleveland, Ohio 44106
}

Nicotinic acetylcholine receptors (nAChRs) mediate ganglionic transmission in the peripheral autonomic nervous system in mammals. Functional neuronal nAChRs have been shown to assemble from a combination of $\alpha$ and $\beta$ subunits, including $\alpha 3$, $\alpha 5, \alpha 7, \beta 2$, and $\beta 4$ in RNA-injected oocytes, but the subunit composition of functional neuronal $\mathrm{nAChRs}$ in vivo in mammals remains unknown. We examined the subunit composition of functional $n A C h R s$ in the intracardiac parasympathetic ganglion in a physiologically intact system in vivo. We report here that localized perfusion of the canine intracardiac ganglion in situ with an antagonist specific for nAChRs containing an $\alpha 3 / \beta 2$ subunit interface ( $\alpha$-conotoxin MII 100-200 nM) resulted in reversible attenuation of the sinus cycle length $(\mathrm{SCL})$ response by $\sim 70 \%$ to electrical stimulation of the preganglionic vagus nerve. Perfusion with antagonist specific for receptors containing an $\alpha 3 / \beta 4$ subunit interface ( $\alpha$-conotoxin AulB $1 \mu \mathrm{M})$ resulted in attenuation in SCL responses ( $20 \%)$ compared with baseline when applied by itself, but not in animals pretreated with $\alpha$-conotoxin MII. Perfusion of the ganglion with $\alpha$-bungarotoxin
(1 $\mu \mathrm{M}$, which blocks $\alpha 7$ receptors) caused a reduction in SCL response by $\sim 30 \%$ compared with baseline when perfused on its own and when added after blockade with MII and AulB. Perfusion with hexamethonium bromide resulted in complete blockade of ganglionic transmission, confirming total perfusion of the ganglion and the nicotinic nature of ganglionic transmission at this synapse. Immunohistochemistry using monoclonal antibodies against specific nicotinic subunits confirmed the presence of $\alpha 3, \alpha 7, \beta 2$, and $\beta 4$ subunits. We conclude that functional ganglionic transmission in the canine intracardiac ganglion is mediated primarily by receptors containing an $\alpha 3 / \beta 2$ subunit interface, with a smaller contribution by receptors containing $\alpha 7 \mathrm{nAChRs}$. Despite the presence of $\beta 4$ subunits in functional channels, a contribution of a distinct $\alpha 3 / \beta 4$ receptor population that does not include an $\alpha 3 / \beta 2$ subunit interface was less clear.

Key words: nicotinic receptor; $\alpha$-conotoxin; neuronal; parasympathetic; cardiac; ganglion; acetylcholine
Ganglionic transmission in peripheral autonomic neurons is mediated by nicotinic acetylcholine receptors (nAChRs) (Fee et al., 1987). nAChRs can be composed of various combinations of heterologous subunits that impart different ionic and ligand binding characteristics allowing for diverse physiological functions (Patrick et al., 1993; McGehee and Role, 1995). The composition of nicotinic receptors responsible for ganglionic transmission in mammalian autonomic neurons currently is unknown. Investigation into the subunit composition of functional receptors may provide insight into pathogenic mechanisms of autonomic nervous dysfunction and pharmacological targets in various disease states, as well as increase understanding of the importance of nAChR diversity.

Neuronal nAChRs have been shown to assemble in vitro from a combination of $\alpha$ - and $\beta$-subunits including $\alpha 2-\alpha 9$ and $\beta 2-\beta 4$ (Listerud et al., 1991; Vernallis et al., 1993). Rat intracardiac neurons can express $\alpha 2-\alpha 9$ and $\beta 2-\beta 4$ subunits, although not all neurons within a ganglion expressed all of these subunits (Poth et al., 1997). In oocytes injected with mRNA for different subunits,

Received Jan. 13, 2000; revised April 5, 2000; accepted April 11, 2000.

This work was supported by the Medical Research Service of the Department of Veterans Affairs and National Institutes of Health Grants HL50669 (M.E.D.), NS12651 (R.E.Z.), MH53631 (J.M.M.), and GM48677 (J.M.M.).

Correspondence should be addressed to Dr. Mark Dunlap, Veterans Affairs Medical Center Medical Research Service 151W, 10701 East Boulevard, Cleveland OH 44106. E-mail: med3@po.cwru.edu.

Copyright (C) 2000 Society for Neuroscience $0270-6474 / 00 / 205076-07 \$ 15.00 / 0$ functional combinations of $\alpha 3 / \beta 2, \alpha 3 / \beta 4, \alpha 3 / \beta 2 / \beta 4, \alpha 3 / \beta 2 / \alpha 5$, $\alpha 3 / \beta 4 / \alpha 5$, and $\alpha 7$ homomers have been detected, although the possibility of other combinations cannot be excluded (Patrick et al., 1993; McGehee and Role, 1995; Wang et al., 1996). The question as to whether neurons in vivo in distinct anatomical sites and/or functional roles express and assemble receptors from all or only a subset of these subunits has been controversial and largely unanswered.

Previous work in chick ciliary ganglia has indicated that the EPSC response to preganglionic stimulation can be attenuated by antagonists to receptors composed of both homomeric $\alpha 7$ and $\alpha 3 / \beta 2$ subunits (Ullian et al., 1997), suggesting that synaptic currents are mediated by a combination of these two receptors. Despite the existence of a postsynaptic current contributed by $\alpha 7$ receptors in the ciliary ganglion (Z hang et al., 1996; Ullian et al., 1997), pharmacological blockade of $\alpha 7$ receptors has failed to show any functional effect on ganglionic transmission (Duggan et al., 1976; Loring et al., 1984; Mandelzys et al., 1995; Sargent and Garrett, 1995). Furthermore, $\alpha 7$ receptors are primarily extrasynaptic in chick ciliary neurons and thus are not likely to be anatomically positioned for a role in rapid synaptic transmission (Jacob and Berg, 1983; Horch and Sargent, 1995). This has raised the question over the past decade as to whether $\alpha 7$ receptors play a functional role in ganglionic transmission despite their anatomical presence in neurons. More recently, the identification of a novel, slowly desensitizing current mediated by $\alpha 7$ receptors in 
neurons isolated from rat intracardiac ganglia has suggested that $\alpha 7$ may have different functional roles dependent on the physiology and location of the neuronal population (Cuevas and Berg, 1998). In addition, single-channel receptor currents that do not conform to $\alpha 7$ homomeric channels can be modified by antisense "knockout" of $\alpha 7$, indicating that these subunits may contribute to cellular currents by combining with other $\alpha$ and $\beta$ subunits (Yu and Role, 1998a,b).

To date, these studies have shared the common limitation of being conducted in isolated, "nonphysiological" conditions. Such conditions may mask and/or provide artifactual evidence for functional roles of subunits located at perijunctional or specialized synaptic sites as well as provide incomplete information based primarily on contribution to EPSCs. Additionally, although the use of immunohistochemistry and molecular biology has provided evidence for the physical presence of subunits, very little information has been gained about the relationship between subunit diversity and in vivo receptor function and physiology. The purpose of this investigation was to determine the functional contributions of various nicotinic receptor subunits to ganglionic transmission in vivo in parasympathetic neurons innervating the heart in a physiologically intact system. We show here that a large component of ganglionic transmission in canine intracardiac neurons is mediated by distinct populations of receptors containing an $\alpha 3 / \beta 2$ subunit interface and $\alpha 7$. Although we also show a smaller functional role for $\alpha 3 / \beta 4$-like receptors, the existence of this subunit combination as a distinct population is less clear.

\section{MATERIALS AND METHODS}

Animals and surgery. All procedures were performed according to guidelines for the care and use of laboratory animals at Case Western Reserve University and the Cleveland Veterans Affairs Medical Center. Adult, male Beagle dogs (Covance, Kalamazoo, MI) were induced with sodium thiopental and anesthetized with $\alpha$-chloralose until toe pinch reflex was absent. Supplemental chloralose was given every $30 \mathrm{~min}$ as needed. After endotracheal intubation, the dogs were placed on a microprocessor controlled respirator (Engler Corporation, Hialeah, FL). Blood gas and $\mathrm{pH}$ were tightly controlled, and a heating blanket maintained temperature in the physiological range. The femoral artery and vein were cannulated for continuous blood pressure monitoring and drug administration. The vagus nerve trunks were dissected and isolated at the cervical level for preganglionic stimulation through a single midline incision. Each nerve trunk was ligated and sectioned to prevent proximal conduction to the brain. A bipolar electrode was inserted into the caudal remnant of the right vagus nerve for stimulation. The right vagus was used for stimulation because it has preferential input to the sino-atrial (SA) node (Hamlin and Smith, 1968). A right thoracotomy was made at the fourth intercostal space, and a bipolar electrode was placed near the atrial appendage for recording of an electrogram (electrical bursts) that was used to measure sinus cycle length (SCL) directly from the heart. SCL was used as an index of organized SA node activity, which is predominantly under vagal and sympathetic control. The sinus node artery, which arises from a branch of the right coronary artery, perfuses the pulmonary vein complex fat pad, a site that contains the ganglia of neurons specifically innervating the SA node (Fee et al., 1987; Billman et al., 1989). This artery was cannulated to provide the means for direct localized perfusion of the intracardiac parasympathetic ganglion. We perfused the artery with oxygenated standard physiological Tyrode's solution at a rate of $\sim 2 \mathrm{ml} / \mathrm{min}$, which was sufficient to maintain forward flow in the perfused area while generating a physiological pressure of $80-140 \mathrm{mmHg}$ in most dogs. Solution reservoirs were warmed to $37^{\circ} \mathrm{C}$ and gassed with $97 \% \mathrm{O}_{2}-3 \% \mathrm{CO}_{2}$. By turning a stopcock, we could selectively switch from control solution to one containing antagonists without changing any other parameters. Various antagonists specific for different combinations of receptor subunits were used.

Drugs and solutions. Antagonists used in this study included $\alpha$-conotoxin MII 100-200 nM [antagonist specific for nAChRs containing $\alpha 3 / \beta 2$ interface (Cartier et al., 1996)], $\alpha$-conotoxin AuIB $1 \mu \mathrm{M}$ [antagonist for nAChRs containing $\alpha 3 / \beta 4$ interface (Luo et al., 1998)], $1 \mu \mathrm{M}$ $\alpha$-bungarotoxin ( $\alpha$-BgTx, antagonist for $\alpha 7 \mathrm{nAChRs),} \mathrm{and} \mathrm{hexametho-}$ nium bromide $(5 \mathrm{mg})$. The conotoxins were dissolved in $0.2 \mathrm{mg} / \mathrm{ml}$ BSA in the perfusion system to prevent the toxin from sticking to the perfusion glassware and tubing. $\alpha$-BgTx was purchased from both Sigma (St. Louis, MO) and Biotoxins (St. Cloud, FL). We used two different sources because previous reports have shown that some $\alpha$-BgTx may contain neuronal bungarotoxin (Loring and Zigmond, 1988). $\alpha$-BgTx from Biotoxins is physiologically assayed after purification to ensure that there is no neuronal bungarotoxin present. We felt that this was important because neuronal bungarotoxin blocks non- $\alpha 7$ receptors, and this would give false evidence for a functional role of $\alpha 7$. Hexamethonium bromide blocks neuronal ganglionic nicotinic receptors via competitive binding to the receptor site without specificity for neuronal subunits and was used in this study as a positive control for inducing ganglionic blockade.

Protocol. Vagal stimulations (preganglionic) were performed in a dose-response manner at 3,5 , and $10 \mathrm{~Hz}$ using $8 \mathrm{~V}$ and a pulse-width of $1 \mathrm{msec}$. Atrial electrogram and electrocardiogram (ECG) signals were recorded for $30 \mathrm{sec}$ of baseline, $30 \mathrm{sec}$ of stimulation, and $30 \mathrm{sec}$ recovery for the assessment of postganglionic responses to preganglionic stimulation. Sufficient time was given between stimulations to allow heart rate to return to prestimulation levels. After making recordings under control conditions, the perfusate reservoir was switched to one that contained one of the antagonists. Perfusion was maintained for at least $15 \mathrm{~min}$ to allow complete delivery of the antagonist to the ganglion before repeating the stimulations. Once recordings under antagonist-perfused conditions were obtained, we then washed out the antagonist by switching back to plain Tyrode's solution to ensure that the decreased response was not caused by decreased viability of the preparation over time. The same antagonist was then either reperfused to show that the effect was repeatable, or the reservoir was switched to one that contained a different antagonist. Hexamethonium was given at the completion of each protocol via the same means to determine the completeness of perfusion of the ganglion.

Data capture and analysis. ECG and electrogram signals were captured at $500 \mathrm{~Hz}$ with an analog-to-digital converter (Gould Instruments, Cleveland, $\mathrm{OH}$ ), but only SCL was used for data analysis. SCL, which is the time between successive spontaneous electrical bursts from the sinus node, was graphically and numerically plotted on-line in real time by built-in software macros. Quantitative analysis of sinus cycle length was made using SCL values averaged over $10 \mathrm{sec}$ during baseline and $15 \mathrm{sec}$ during stimulation. Statistical significance was determined by a paired or unpaired $t$ test where appropriate after testing for equality of variance using SigmaStat software (SPSS, Chicago, IL). For samples with unequal variance, statistical significance was determined by using a Wilcoxon signed rank test.

Immunohistochemistry. Immediately after the heart was excised, either the entire heart or a branch of the coronary artery supplying the ganglion was perfused with $4 \%$ paraformaldehyde. The tissue then was placed in paraformaldehyde for $2-12 \mathrm{hr}$ and transferred to $15 \%$ sucrose (PBS) overnight. Before sectioning, the tissue was immersed in $30 \%$ sucrose overnight for cryoprotection at $4^{\circ} \mathrm{C}$. The tissue was then frozen in OCT Compound (Miles, Elkhart, IN), and 10-20 $\mu \mathrm{m}$ sections were cut on a cryostat microtome at $-24^{\circ} \mathrm{C}$. The frozen sections were placed onto gelatin-coated slides and frozen at $-80^{\circ} \mathrm{C}$. Sections were incubated overnight with one antibody or a combination of mAb210, mAb306, $\mathrm{mAb313}, \mathrm{mAb} 295$, and polyclonal $\beta 4$ at a final concentration of 1:5000 or glial fibrillary acid protein (GFAP) at 1:2500 (see Table 1). Fluorescence was imparted via Cy3- or Cy2-conjugated donkey anti-rat, anti-mouse, or anti-rabbit secondary antibody. A no-primary control was performed for each sample of tissue for each secondary antibody, and background was determined by comparison of the adjacent cardiac muscle with the ganglion.

\section{RESULTS}

\section{Perfusion of the ganglion with $\alpha$-conotoxin MII}

SCL response to preganglionic stimulation of the right cervical vagus was examined before and after perfusion with $\alpha$-conotoxin MII, an antagonist for $\mathrm{nAChRs}$ containing an $\alpha 3 / \beta 2$ subunit interface (Fig. 1). Stimulations under both control and conotoxinperfused conditions resulted in an immediate increase of sinus cycle length. There was no consistent difference in the rate of onset of the response between antagonist-perfused and control 

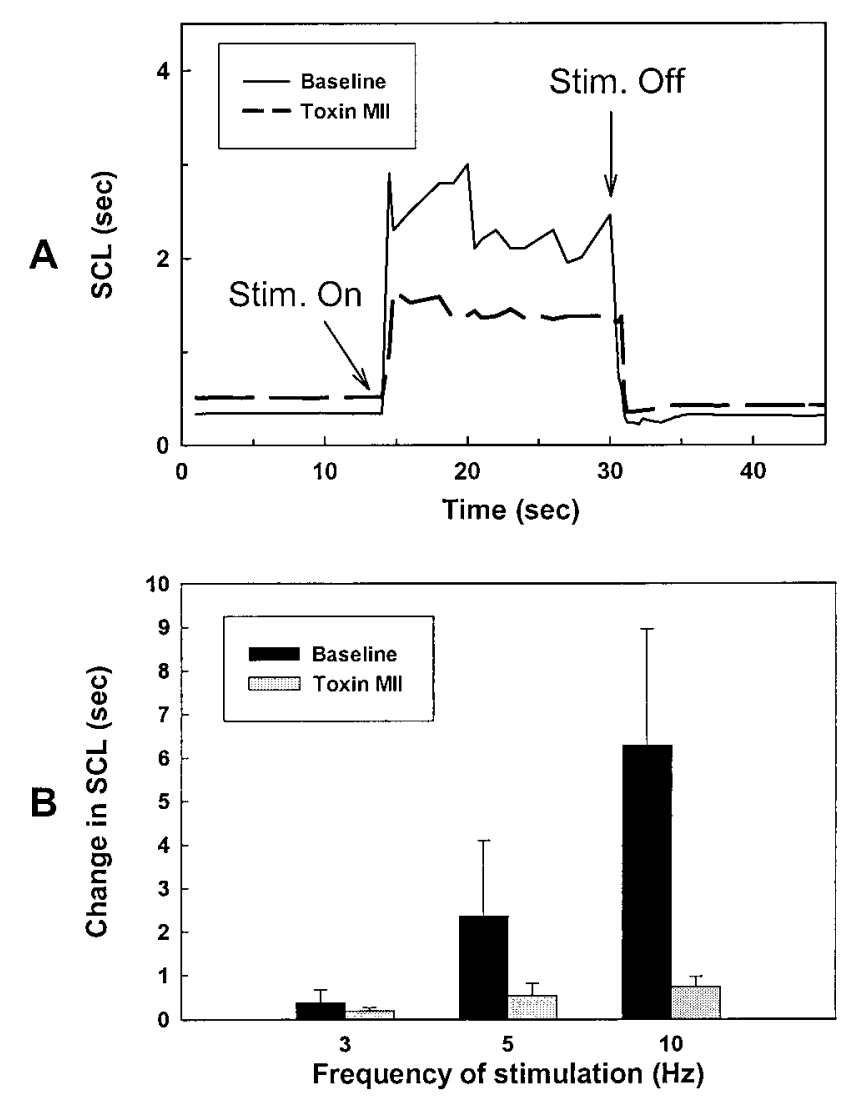

Figure 1. A, Plot of raw data showing change in SCL from baseline in response to preganglionic stimulation before and after perfusion with $\alpha$-conotoxin MII in the same animal. Note that there is no apparent difference in rate of onset or recovery from stimulation between the two conditions. $B$, Group mean postganglionic response to preganglionic stimulation at 3,5 , and $10 \mathrm{~Hz}$ before and after $\alpha$-conotoxin M II $(200 \mathrm{nM}) ; n=$ $9, p<0.05$ using paired $t$ test or Wilcoxon signed rank test at each stimulation frequency. Vertical bars are SEM in this and other figures.

conditions. Figure $1 B$ illustrates the mean group change in SCL (from baseline) in response to vagal stimulation at three frequencies of stimulation for both control and MII-perfused conditions. The increase in SCL was reduced at all levels of stimulation after drug treatment (control: $381 \pm 90,2349 \pm 175,6290 \pm 267 \mathrm{msec}$ vs MII perfused: $200 \pm 70,541 \pm 279,728 \pm 252 \mathrm{msec}, n=9, p<$ 0.05 by paired $t$ test at 3,5 , and $10 \mathrm{~Hz}$ stimulation), for an average reduction of $\sim 70 \%$.

\section{Perfusion of the ganglion with $\alpha$-conotoxin AulB}

Figure 2 shows the group mean response when conotoxin AuIB $(\alpha 3 / \beta 4)$ was perfused at $1 \mu \mathrm{M}$ (control: $468 \pm 65,762+109,1574$ + 266 vs AuIB: $289+63,479.8+90,1227+297$ msec at 3, 5, and $10 \mathrm{~Hz}$, respectively; $n=7)$. Perfusion with toxin AuIB resulted in a reduction in ganglionic transmission $(\sim 20 \%, p=<0.05$ except at $10 \mathrm{~Hz}, p=0.054$ by paired $t$ test). To examine the possibility that $\alpha 3 / \beta 4$ subunits were part of receptors that also contained $\beta 2$, we tested AuIB after perfusion with MII (Fig. 3). Perfusion with AuIB after MII did not have a significant effect on ganglionic transmission $(172.6 \pm 12.4,260 \pm 41,501.6 \pm 122.8$ msec before AuIB, vs $150 \pm 49,262 \pm 137,628 \pm 373$ msec after AuIB at 3,5 , and $10 \mathrm{~Hz}, p>0.05$ by paired $t$ test at each stimulation frequency), suggesting that $\alpha 3 / \beta 4$ subunits do not form a distinct population of receptors that contribute significantly to ganglionic transmission in the heart.

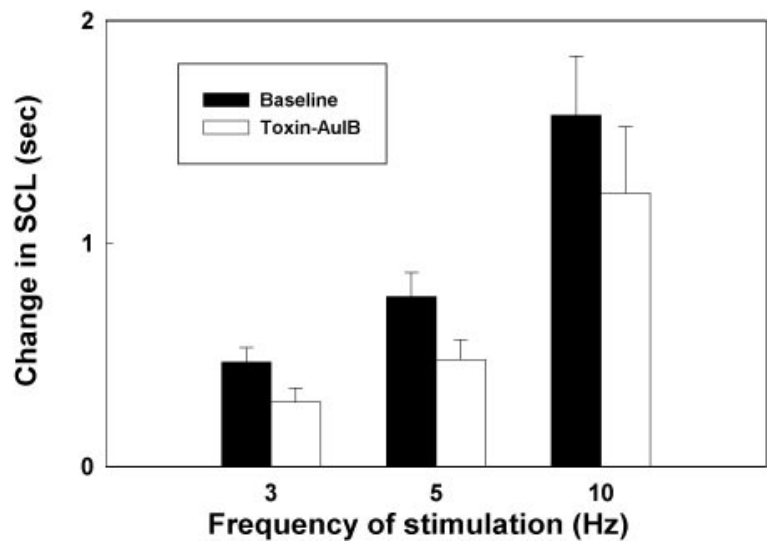

Figure 2. Group mean response to preganglionic stimulation at 3, 5, and $10 \mathrm{~Hz}$ before and after $\alpha$-conotoxin AuIB $(1 \mu \mathrm{M}) ; n=7, p<0.05$ using paired $t$ test at 3 and $5 \mathrm{~Hz}$ and $p=0.054$ at $10 \mathrm{~Hz}$.

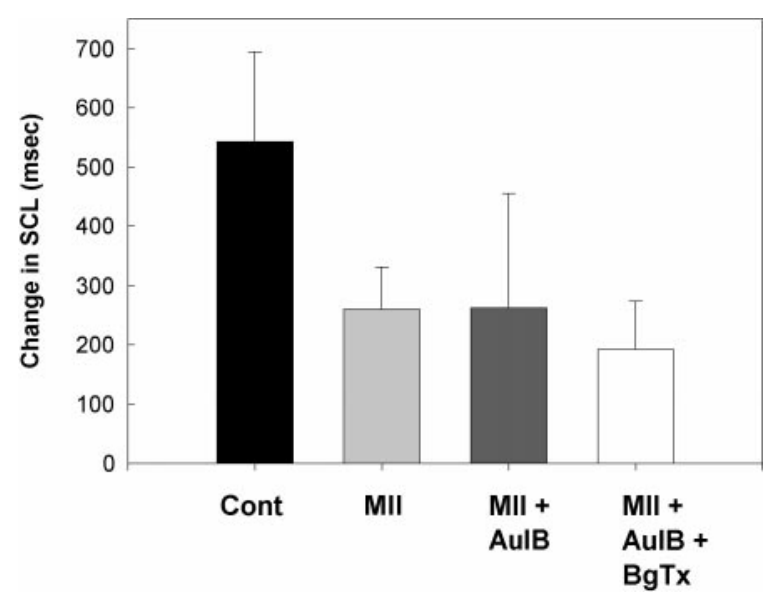

Figure 3. Effects of multiple antagonists on ganglionic transmission at 3 $\mathrm{Hz}$ stimulation. Cont, Baseline response after 20 min perfusion with plain Tyrode's solution; $M I I$, response after perfusion with $200 \mathrm{nM} \alpha$-conotoxin MII for $20 \mathrm{~min} ; M I I+A u I B$, response after perfusion with $1 \mu \mathrm{M}$ $\alpha$-conotoxin AuIB (coapplied with MII) for 20 min, $p>0.05$; $M I I+A u I B$ $+\alpha$-BgTx, response after perfusion with $1 \mu \mathrm{M} \alpha$-bungarotoxin (coapplied with MII and AuIB) for $35 \mathrm{~min} ; p<0.05, n=4$.

\section{Perfusion of the ganglion with $\alpha$-bungarotoxin}

To examine the potential role of $\alpha 7 \mathrm{nAChRs}$ in ganglionic transmission, we recorded the SCL response to preganglionic nerve stimulation before and after perfusion with BgTx (Fig. 4). Perfusion of $\alpha$-BgTx showed an average $30 \%$ attenuation of ganglionic transmission $(363.2 \pm 65,580.7 \pm 95,1656.5 \pm 352 \mathrm{msec}$ at baseline, vs $229.2 \pm 57,397.25 \pm 68,1115 \pm 250 \mathrm{msec}$ after BgTx, $n=5, p<0.05$ by one-tailed, paired $t$ test at each stimulation) and was not reversible at $1 \mathrm{hr}$ after switching back to control solution. To test whether the effect of BgTx was independent of receptor populations blocked by MII, we perfused BgTx after blockade with $\alpha$-conotoxin MII and AuIB together (Fig. 3). The effect of BgTx persisted in the presence of MII $(150 \pm 49,262 \pm$ 137, $628 \pm 373 \mathrm{msec}$ before adding BgTx, vs $126 \pm 21.5$, 192.47, $332 \pm 106$ msec after BgTx, $p<0.05$ by one-tailed $t$ test at each stimulation frequency), suggesting that $\alpha 7$ subunits comprise a functionally distinct population of receptors.

\section{Effects of hexamethonium bromide}

To assess whether noncholinergic receptors contributed to ganglionic transmission in our preparation, we perfused the ganglion 


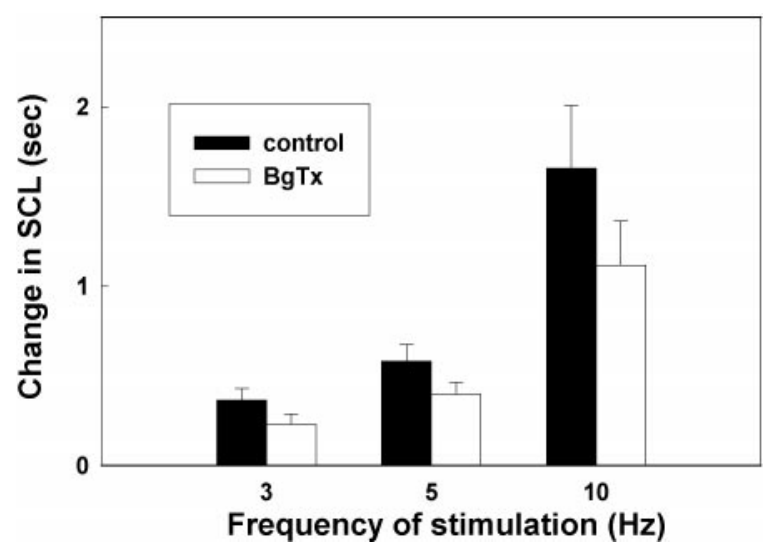

Figure 4. Group mean response to preganglionic stimulation at 3, 5, and $10 \mathrm{~Hz}$ before and after $\alpha$-BgTx $(1 \mu \mathrm{M}) ; n=5, p<0.05$ using paired $t$ test.

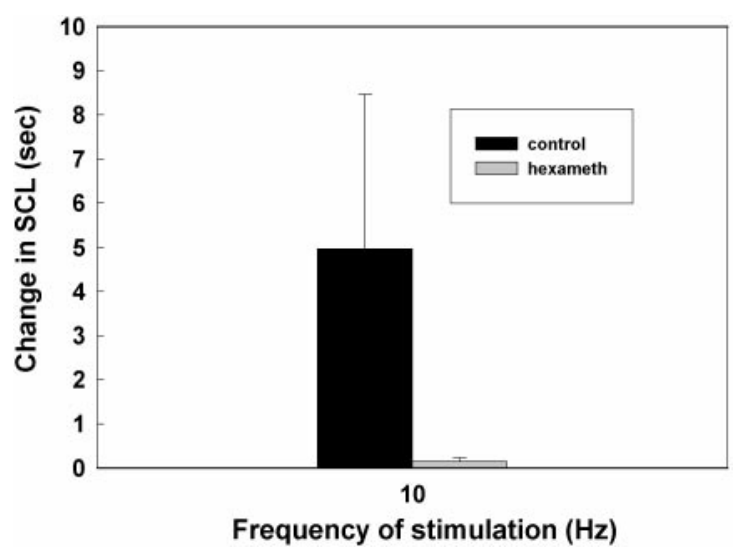

Figure 5. Effect of hexamethonium bromide $(5 \mathrm{mg})$ on ganglionic transmission. Perfusion of the ganglion for 5 min with hexamethonium completely abolished postganglionic response to preganglionic stimulation confirming that the entire ganglion was perfused and that synaptic transmission was completely mediated by nAChRs. $n=5, p<0.01$ using paired $t$ test.

at the completion of each study with hexamethonium bromide. Perfusion with hexamethonium totally abolished SCL response to preganglionic stimulation at $10 \mathrm{~Hz}$ (Fig. 5) in all preparations (control $4960 \pm 3500$ vs $140 \pm 90 \mathrm{msec}$ at $10 \mathrm{~Hz}, n=5, p<0.01$ using paired $t$ test), confirming nAChR-mediated transmission.

\section{Immunofluorescence identification of nicotinic receptor subunits}

To confirm the presence of the various subunits tested in the pharmacological studies, we conducted immunohistochemical studies using monoclonal antibodies specific for nAChR subunits (Table 1). mAb313, mAb295, and mAb306 were used to confirm the anatomical presence of $\alpha 3, \beta 2$, and $\alpha 7$ subunits, respectively. Figure 6 shows results obtained with these three monoclonal antibodies and a polyclonal antibody for $\beta 4$ subunits. The pattern of staining was different for each of the antibodies used, but signal was strong for each subunit compared with background muscle staining for each antibody. No-primary controls for each secondary antibody showed no evidence for nonspecific binding. To ensure that the labeling was exclusively neuronal, we conducted double staining with GFAP. As seen in Figure 7, GFAP and mAb210 (specific for $\alpha 1, \alpha 3$, and $\alpha 5$ ) were localized in distinct regions without any overlap.

\begin{tabular}{llll}
\hline \multicolumn{3}{l}{ Table 1. Description of antibodies used in study } & \\
Antibody & Recognizes & Host & Immunogen \\
\hline $\mathrm{mAb} 210$ & $\alpha 1, \alpha 3, \alpha 5$ & Rat & Human $\alpha 3$ \\
$\mathrm{mAb} 313$ & $\alpha 3$ & Rat & Chick $\alpha 3$ \\
$\mathrm{mAb} 306$ & $\alpha 7$ & Mouse & Chick $\alpha 7$ \\
$\mathrm{mAb} 295$ & $\beta 2$ & Rat & Human $\beta 2$ \\
Anti-GFAP & GFAP & Rabbit & Mouse \\
Polyclonal & $\beta 4$ & Rabbit & Rat
\end{tabular}

mAb 295 courtesy of Dr. Jon Lindstrom. Polyclonal anti- $\beta 4$ courtesy of Dr. Scott W. Rogers. Other antibodies were purchased from RBI (Natick, MA). (See 1991 RBI catalog.)

\section{DISCUSSION}

This study aimed to determine the functional nAChR subtypes responsible for ganglionic transmission in peripheral parasympathetic neurons in dogs. Our results show that nAChRs responsible for a large portion of ganglionic transmission in canine intracardiac parasympathetic neurons contain an $\alpha 3 / \beta 2$ subunit interface. In addition, a functional contribution from receptors that contain $\alpha 7$ was evident, but a functional role for receptors that contain $\alpha 3 / \beta 4$ without $\beta 2$ could not be demonstrated.

The large contribution to ganglionic transmission by $\alpha 3 / \beta 2$-like receptors is consistent with previous findings in chick ciliary ganglion (Ullian et al., 1997). This study indicated that blockade of $\alpha 3 / \beta 2$ receptors using MII abolished a major component of the EPSC and blocked ganglionic transmission. Our results show that ganglionic transmission was attenuated by $\sim 70 \%$ at concentrations within the range of specificity for receptors containing $\alpha 3 / \beta 2$ (Cartier et al., 1996; Harvey et al., 1997). It is possible that the component not blocked by $\alpha$-conotoxin MII was mediated by a different population of receptors or by neurons that were outside the perfused region. To exclude this latter possibility, we perfused the region with hexamethonium bromide, a nicotinic receptor antagonist that blocks all neuronal nicotinic receptors. This resulted in complete blockade, confirming that all transmission at the synapse was mediated by nAChRs and that the entire ganglion was being perfused without alternate inputs to the SA node. Another possibility for the incomplete blockade is that acetylcholine released from the presynaptic nerve terminal may have been able to displace MII from its binding site in a competitive fashion. It was not feasible to increase the concentration of MII beyond $250 \mathrm{~nm}$ to test this possibility because of the loss of specificity of MII at a higher concentration of MII. Although evidence in chick ciliary ganglion shows that EPSCs mediated by $\alpha 3 / \beta 2 \mathrm{nAChRs}$ can be abolished with $50 \mathrm{~nm}$ MII (Ullian et al., 1997), these studies were conducted in isolated neurons in vitro, which is not comparable to our in vivo system. In view of our finding that higher stimulation intensities elicited greater responses in the presence of MII, it seems likely that competitive displacement of MII could have contributed to the incomplete blockade of ganglionic transmission in these experiments.

The notion that pharmacological blockade of receptors containing $\alpha 3 / \beta 4$ subunits would result in attenuation of ganglionic transmission is supported by previous findings. Vernallis et al. (1993) have shown previously that AChRs in ganglionic extracts that contained immunoreactivity to $\alpha 3$ and $\beta 2$ subunits also contained $\beta 4$ subunits. The presence of $\beta 4$ subunits also has been described previously in mammalian intracardiac neurons (Poth et al., 1997), and the $\beta 4$ subunit has been shown to assemble with the $\alpha 3$ subunit (Vernallis et al., 1993), suggesting that $\alpha 3 / \beta 4$ receptor 

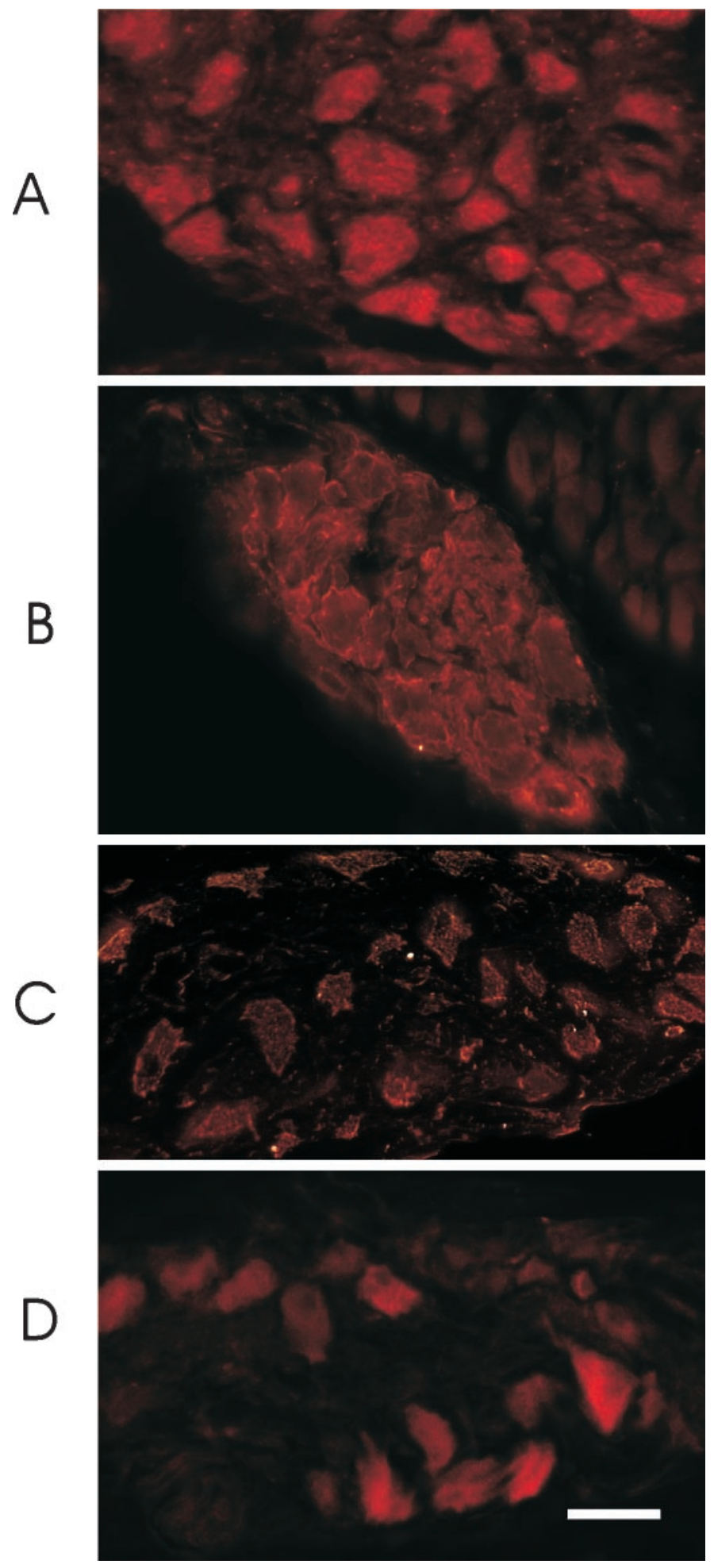

Figure 6. Immunohistochemistry showing anatomical presence of multiple nAChR subunits with cyanine-labeled monoclonal antibodies. $A$, mAb313 ( $\alpha 3$ subunit); $B$, mAb295 ( $\beta 2$ subunit); $C$, mAb306 ( $\alpha 7$ subunit); $D$, polyclonal $\beta 4$ ( $\beta 4$ subunit). Background staining of cardiac muscle can be seen in the top right corner of $B$. No-primary controls did not show nonspecific binding for any of the secondary antibodies. Scale bar, $25 \mu \mathrm{m}$. should comprise a functional receptor population. However, we found no significant contribution of receptors containing an $\alpha 3 / \beta 4$ subunit interface to functional ganglionic transmission after blockade of $\alpha 3 / \beta 2$ receptors. Biophysical data in Xenopus oocytes suggests that $\alpha 3 / \beta 4$ receptors generate a larger current than $\alpha 3 / \beta 2$ (McGehee and Role, 1995). Therefore, if this receptor subtype assembled to the same degree as $\alpha 3 / \beta 2$ as a distinct population, and assuming similar regulation, we should have seen a greater attenuation in ganglionic transmission with toxin AuIB. Our data therefore imply that receptors containing an $\alpha 3 / \beta 4$ subunit interface may not be formed to any large degree as a distinct population and/or may only assemble into functional channels along with $\alpha 3, \beta 2$, or other subunits. Another possibility is that $\alpha 3 / \beta 4$ is assembled in the cytoplasm, but the receptor is not transported to the membrane to a significant degree. Our current data, and a recent report showing that mice deficient in the $\beta 4$ subunit do not show gross autonomic dysfunction until cross-bred with $\beta 2$ deficient mice, suggest that $\beta 2$ and $\beta 4$ subunits may coassemble with $\alpha 3$ to form functional nAChRs (Xu et al., 1999).

The finding that blockade of $\alpha 7$ receptors did have an effect on ganglionic transmission is also surprising in light of findings previously reported in the literature. It has been shown that blockade of $\alpha 7$ receptors with $\alpha$-BgTx does not block compound action potentials in chick ciliary ganglion (Loring et al., 1989), presumably because synaptic currents in the presence of $\alpha 7$ blockade are sufficient to reach threshold (Zhang et al., 1996). Other reports have shown clearly that there is a rapid desensitizing current that is blocked with $\alpha$-BgTx (Zhang et al., 1996; Ullian et al., 1997) and that currents are modified by blockade of the $\alpha 7$ subunit (Yu and Role, 1998a). More recently it was shown that $\alpha 7$ receptors mediate a slowly desensitizing current in response to acetylcholine in neurons isolated from the intracardiac ganglion of the rat (Cuevas and Berg, 1998) and that blockade of $\alpha 7$ receptors in chick ciliary ganglion can lead to failure of transmission when stimulated at higher frequencies (Chang and Berg, 1999). These findings have lead investigators to postulate that $\alpha 7$ may play a physiological role in ganglionic transmission depending on the function and environment of the neuron. A concern in the former study was that with artificial delivery of acetylcholine to the dissociated neuron there might be a nonphysiological activation of $\alpha 7$ receptors, which has been shown by a number of groups to be perisynaptic (Jacob and Berg, 1983; Loring et al., 1985). On the other hand, it is possible that the role of $\alpha 7$ subunits is species, developmentally, and/or anatomically dependent and the $\alpha 7$ subunit contributes to a greater component of an EPSC in cardiac neurons compared with adult chick ciliary ganglion. The contribution of $\alpha 7$ to ganglionic transmission in this study supports the latter.

Another possibility raised by the anatomical localization of $\alpha 7$ subunits outside the synaptic region is that $\alpha 7$ may play a role at higher intensities of stimulation. In such a model, $\alpha 7$ receptors are not activated at lower stimulation intensity (firing rate) because any released acetylcholine is quickly bound to receptors in the main synaptic region and/or rapidly degraded by acetylcholinesterase. At higher stimulation intensity, more acetylcholine is available for longer periods of time and therefore able to diffuse to the anatomically distant $\alpha 7$ receptors. Although it did not reach significance in our study, blockade of these receptors tended to result in greater attenuation of ganglionic transmission at higher stimulation intensities (Fig. 4), suggesting that $\alpha 7$ may contribute a greater component to postsynaptic currents at higher levels of the physiological range. 

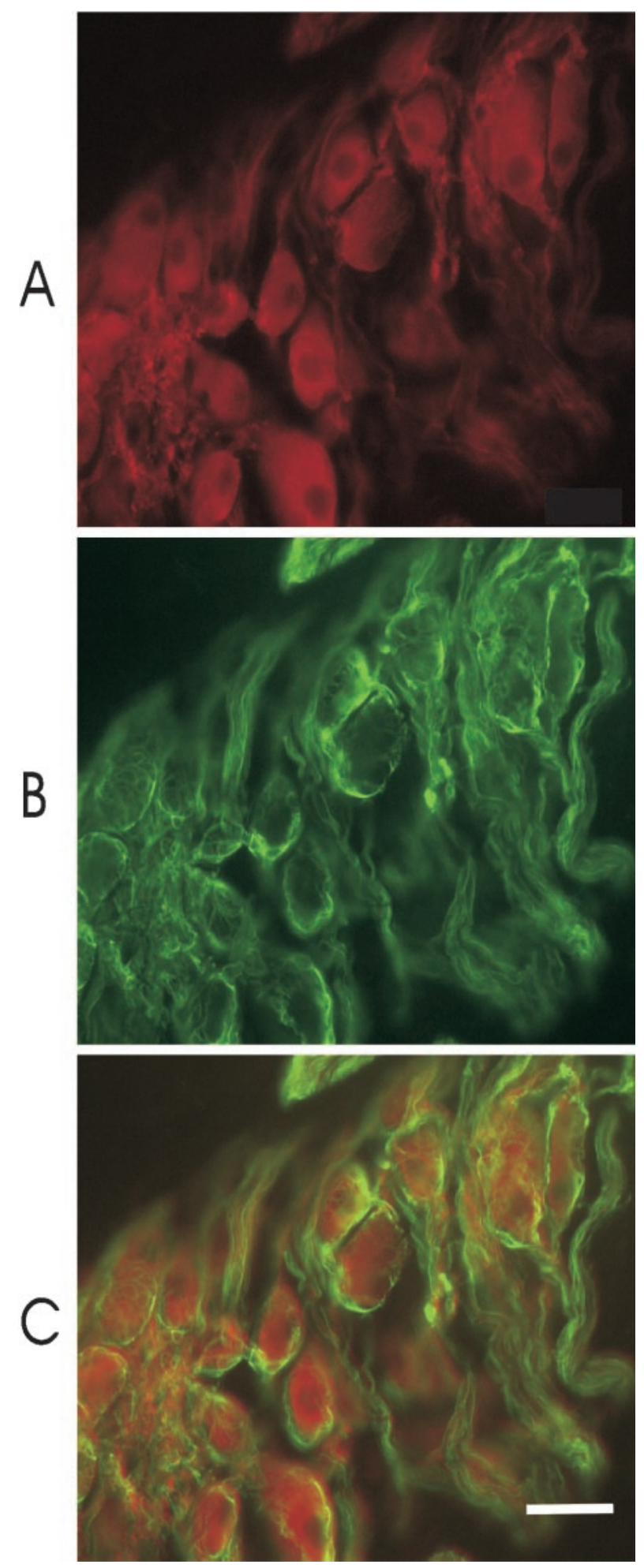

Figure 7. Image showing double staining immunofluorescence for GFAP and mAb210. $A$, mAb210 only; $B$, GFAP only; $C$, both GFAP and $\mathrm{mAb} 210$. Note that GFAP totally surrounds and envelopes the neuron with a mesh-like covering. There is no overlap of GFAP and mAb210, confirming that the fluorescence seen with mAb210 was localized to neurons only. Scale bar, $25 \mu \mathrm{m}$.
Immunohistochemistry confirmed the presence of $\alpha 3, \alpha 7, \beta 2$, and $\beta 4$ subunits. $\alpha 3$ and $\beta 4$ subunits appeared diffusely distributed throughout the cytoplasm, whereas $\beta 2$ was predominantly periplasmic. An interesting observation was the localization of $\alpha 7$ subunits, which appeared punctate, suggesting storage or transport of the subunit in vesicles. The implications of this finding are unclear, but the different intracellular localization may represent a physiologically distinct function of $\alpha 7$ receptors. A particularly intriguing possibility is the potential specialized localization of $\alpha 7$ receptors at somatic spines where increased calcium handling may occur through these receptors. Under these circumstances, $\alpha 7$ receptors could be securely compartmentalized to specific regions, as suggested by Shoop and colleagues (1999).

The mechanism(s) by which perfusion with the various antagonists produces blockade warrants some discussion. Possible mechanisms that may explain the results reported here can be described by two hypotheses. Hypothesis A is that decreased ganglionic transmission after perfusion with antagonist is caused by an elimination of a population of receptors that contributes to the EPSC, thereby resulting in threshold being reached less frequently. Current evidence in support of this hypothesis lies in the finding that multiple subtypes of receptor can contribute to the EPSC on single neurons (Ullian et al., 1997). Hypothesis B is that individual neurons predominantly express one type of receptor, and perfusion with antagonist results in total blockade of those neurons, leaving other neurons that express different receptor populations active to contribute to the EPSC. Evidence to support this hypothesis comes from the finding that not all neurons express the same population of nicotinic receptor, and that some receptor subunits are expressed in only a small percentage of total neurons (Poth et al., 1997). On the other hand, a combination of these two mechanisms may be the most likely explanation for our findings, although our data support hypothesis A because all neurons in the ganglia stained positive for each subunit tested.

A limitation of our study is that although we are able to block various combinations of nicotinic subunits, this does not exclude the possibility that other subunits are present within the same pentamer. This possibility has been explored previously in vitro in some detail, and it appears that functional receptors can be composed from multiple subunit species in various combinations (Listerud et al., 1991; Yu and Role, 1998a). Data from our study suggest that $\alpha 3, \beta 2$, and $\beta 4$ can coassemble to form a functional receptor but that distinct populations of $\alpha 3 / \beta 4$ are not formed. In addition, the possibility exists that the results reported here are a combination of effects on presynaptic as well as postsynaptic $\mathrm{nAChR}$ populations; however, we did not test this issue.

Why do neurons express multiple subtypes of receptor and use different populations to differing degrees in mediating ganglionic transmission? One possibility is that the different characteristics of various subunit populations may allow for an increased spectrum of information to be passed on to the postsynaptic neuron. The total number of vagal neurons innervating the SA node in dogs is approximately 200 (Yuan et al., 1994), which is remarkable in view of the critical and powerful influence that the parasympathetic nervous system has over heart rate control. In addition, it has become evident more recently that the intrinsic cardiac innervation may involve a complex network analogous to the intrinsic nervous system of the gut (Armour et al., 1998). This type of system may use different populations of nicotinic receptors for relay of information from divergent sources. In addition, the nature of nerve traffic varies in different anatomical and functional roles. It may be possible that the subunit composition 
of nAChRs at different anatomic sites is dictated by the intensity and nature of nerve impulses needed for functional efficiency. Although such a function for nicotinic receptors is speculative at this stage, it clearly identifies the need for investigating the in vivo role of nicotinic receptor function in the future.

\section{REFERENCES}

Armour JA, Collier K, Kember G, Ardell JL (1998) Differential selectivity of cardiac neurons in separate intrathoracic autonomic ganglia. Am J Physiol 274:R939-R949.

Billman GE, Hoskins RS, Randall DC, Randall WC, Hamlin RL, Lin YC (1989) Selective vagal postganglionic innervation of the sinoatrial and atrioventricular nodes in the non-human primate. J Auton Nerv Syst 26:27-36.

Cartier GE, Yoshikami D, Gray WR, Luo S, Olivera BM, McIntosh JM (1996) A new alpha-conotoxin which targets alpha3/beta2 nicotinic acetylcholine receptors. J Biol Chem 271:7522-7528.

Chang KT, Berg DK (1999) Nicotinic acetylcholine receptors containing alpha7 subunits are required for reliable synaptic transmission in situ. J Neurosci 19:3701-3710.

Cuevas J, Berg DK (1998) Mammalian nicotinic receptors with alpha7 subunits that slowly desensitize and rapidly recover from alphabungarotoxin blockade. J Neurosci 18:10335-10344.

Duggan AW, Hall JG, Lee CY (1976) Alpha-bungarotoxin, cobra neurotoxin and excitation of Renshaw cells by acetylcholine. Brain Res 107:166-170.

Fee JD, Randall WC, Wurster RD, Ardell JL (1987) Selective ganglionic blockade of vagal inputs to sinoatrial and/or atrioventricular regions. J Pharmacol Exp Ther 242:1006-1012.

Hamlin RL, Smith CR (1968) Effects of vagal stimulation on S-A and A-V nodes. Am J Physiol 215:560-568.

Harvey S, McIntosh J, Cartier G, Maddox F, Luetje C (1997) Determinants of specificity for alpha-conotoxin MII on alpha3/beta2 neuronal nicotinic receptors. Mol Pharmacol 51:336-342.

Horch HL, Sargent PB (1995) Perisynaptic surface distribution of multiple classes of nicotinic acetylcholine receptors on neurons in the chicken ciliary ganglion. J Neurosci 15:7778-7795.

Jacob MH, Berg DK (1983) The ultrastructural localization of alphabungarotoxin binding sites in relation to synapses on chick ciliary ganglion neurons. J Neurosci 3:260-271.

Listerud M, Brussaard AB, Devay P, Colman DR, Role LW (1991) Functional contribution of neuronal AChR subunits revealed by antisense oligonucleotides. Science [Erratum (1992) 255:12] 254: $1518-1521$.

Loring R, Zigmond R (1988) Characterization of neuronal nicotinic receptors by snake venom neurotoxins. Trends Neurosci 11:73-78.

Loring R, Chiappinelli V, Zigmond R, Cohen J (1984) Characterization of a snake venom neurotoxin which blocks nicotinic transmission in the avian ciliary ganglion. Neuroscience 11:989-999.

Loring R, Dahm L, Zigmond R (1985) Localization of alphabungarotoxin binding sites in the ciliary ganglion of the embryonic chick: an autoradiographic study at the light and electron microscopic level. Neuroscience 14:645-660.

Loring RH, Aizenman E, Lipton SA, Zigmond RE (1989) Character- ization of nicotinic receptors in chick retina using a snake venom neurotoxin that blocks neuronal nicotinic receptor function. J Neurosci 9:2423-2431.

Luo S, Kulak JM, Cartier GE, Jacobsen RB, Yoshikami D, Olivera BM, McIntosh JM (1998) $\alpha$-Conotoxin AuIB selectively blocks $\alpha 3 / \beta 4$ nicotinic acetylcholine receptors and nicotine-evoked norepinephrine release. J Neurosci 18:8571-8579.

Mandelzys A, De Koninck P, Cooper E (1995) Agonist and toxin sensitivities of ACh-evoked currents on neurons expressing multiple nicotinic ACh receptor subunits. J Neurophysiol 74:1212-1221.

McGehee DS, Role LW (1995) Physiological diversity of nicotinic acetylcholine receptors expressed by vertebrate neurons. Annu Rev Physiol 57:521-546.

Patrick J, Sequela P, Vernino S, Amador M, Leutje C, Dani JA (1993) Functional diversity of neuronal nicotinic acetylcholine receptors. Prog Brain Res 98:113-120.

Poth K, Nutter TJ, Cuevas J, Parker MJ, Adams DJ, Luetje CW (1997) Heterogeneity of nicotinic receptor class and subunit mRNA expression among individual parasympathetic neurons from rat intracardiac ganglia. J Neurosci 17:586-596.

Sargent PB, Garrett EN (1995) The characterization of alphabungarotoxin receptors on the surface of parasympathetic neurons in the frog heart. Brain Res 680:99-107.

Shoop RD, Martone ME, Yamada N, Ellisman MH, Berg DK (1999) Neuronal acetylcholine receptors with $\alpha 7$ subunits are concentrated on somatic spines for synaptic signaling in embryonic chick ciliary ganglia. J Neurosci 19:692-704.

Ullian EM, McIntosh JM, Sargent PB (1997) Rapid synaptic transmission in the avian ciliary ganglion is mediated by two distinct classes of nicotinic receptors. J Neurosci 17:7210-7219.

Vernallis AB, Conroy WG, Berg DK (1993) Neurons assemble acetylcholine receptors with as many as three kinds of subunits while maintaining subunit segregation among receptor subtypes. Neuron 10: 451-464.

Wang F, Gerzanich V, Wells GB, Anand R, Peng X, Keyser K, Lindstrom J (1996) Assembly of human neuronal nicotinic receptor alpha5 subunits with alpha3, beta2, and beta4 subunits. J Biol Chem 271:17656-17665.

Xu W, Orr-Urtreger A, Nigro F, Gelber S, Sutcliffe CB, Armstrong D, Patrick JW, Role LW, Beaudet AL, De Biasi M (1999) Multiorgan autonomic dysfunction in mice lacking the $\beta 2$ and the $\beta 4$ subunits of neuronal nicotinic acetylcholine receptors. J Neurosci 19:9298-9305.

Yu CR, Role LW (1998b) Functional contribution of the alpha5 subunit to neuronal nicotinic channels expressed by chick sympathetic ganglion neurones. J Physiol (Lond) 509.3:667-681.

Yu CR, Role LW (1998a) Functional contribution of the alpha7 subunit to multiple subtypes of nicotinic receptors in embryonic chick sympathetic neurones. J Physiol (Lond) 509.3:651-665.

Yuan BX, Ardell JL, Hopkins DA, Losier AM, Armour JA (1994) Gross and microscopic anatomy of the canine intrinsic cardiac nervous system. Anat Rec 239:75-87.

Zhang ZW, Coggan JS, Berg DK (1996) Synaptic currents generated by neuronal acetylcholine receptors sensitive to alpha-bungarotoxin. Neuron $17: 1231-1240$. 